\title{
Sustainable Concrete Containing Recycled Aggregates and Pozzolana in Sudan
}

\author{
Eltahir Elshiakh ${ }^{1,}$, , Salma Mahmoud ${ }^{2}$ \\ ${ }^{1}$ Construction Engineering Department, Sudan University of Science \& Technology, Khartoum, Sudan \\ ${ }^{2}$ Civil Engineering Department, University of Science \& Technology, Omdurman, Sudan
}

Email address:

schoolcivil@yahoo.com (E. Elshaikh),salmaymm@gmail.com (S. Mahmoud)

${ }^{*}$ Corresponding author

\section{To cite this article:}

Eltahir Elshiakh, Salma Mahmoud. Sustainable Concrete Containing Recycled Aggregates and Pozzolana in Sudan. American Journal of Construction and Building Materials. Vol. 4, No. 2, 2020, pp. 33-38. doi: 10.11648/j.ajcbm.20200402.11

Received: July 17, 2020; Accepted: August 3, 2020; Published: August 13, 2020

\begin{abstract}
Sustainable trails in the building industry called for preserving the natural resources through the production of green concrete. This is concrete where waste materials are used as at least one of its components, or its production does not lead to environmental destruction through the reduction, reuse or recycling techniques. Experimental results from a study on the potential usefulness of recycled coarse aggregates (RCA) blended with locally available natural Pozzolana are outlined in this paper. Eight concrete mix scenarios were considered: a standard mix with 100\% natural coarse aggregates (NCA), $25 \%$ RCA, 50\% RCA, 75\%RCA, 100\% RCA and no Pozzolana, 100\% RCA and 10\% Pozzolana, 100\% RCA and 20\% Pozzolana, $100 \%$ RCA and 30\% Pozzolana. Slump test was conducted and the results were all within the specific limits. It was conversely realized that the workability decreased in the cases of replacing NCA by RCA with no Pozzolana while an increase was recognized when the Pozzolana was add in the different percentages with the best results achieved with 100\% RCA and $20 \%$ Pozzolana. The compressive strength results were consistent for the different curing ages with the highest strength being acquired with the mix that contained 100\%RCA and 10\% Pozzolana. The results of the durability test revealed better values for the wave length speed value when the NCA was replaced by the RCA. Considering these outcomes, the optimum result was achieved in the case of $100 \% \mathrm{RCA}$ and $10 \%$ Pozzolana. Thus, the experimental results offer good indication for a potential usefulness of RCA proposing a reasonable way for preserving virgin natural materials.
\end{abstract}

Keywords: Compressive Strength, Pozzolana, Recycled Aggregates, Sudan, Workability

\section{Introduction}

Concrete is a heavy, rough building material made from a mixture of cement, fine and coarse aggregates, water and maybe some additives in different proportions produced to meet certain design specifications. For the many negative impacts that the concrete production poses, many researchers classified it as environmentally unfriendly. The fact that concrete production consumes natural resources such as river sand, clays and rocks which will be consumed but not returned back and involves the emission of huge amounts of $\mathrm{CO}_{2}$ during the production of cement-as one of its major constituents- concerns arise from the associated severe negative impact on the environment. Accordingly, sustainable trails in the building industry called for preserving these natural resources through the production of eco-friendly concrete. This is concrete where waste materials are used as at least one of its components or its production does not lead to environmental destruction through the reduction, reuse or recycling techniques.

The call for cement and concrete production sustainability was stressed by [1] with estimated figures on the worldwide production of cement and the associated hazards from the manufacturing process showing how significant is the carbon footprint of the global cement and concrete industry. Being affected by economic and social transformations in societies, urbanization and patterns of population growth has changed entailing consequences of industrialization, globalization and environmental pollution. Global warming is the most important sustainability issue today in the public mind. The World Commission on Environment and Development 
defines sustainability as "meeting the needs of the present without compromising the ability of the future generations to meet their own needs" [2].

Green concrete is thought to be one of the solutions leading to sustainable construction because it "... uses waste material as at least one of its components, or its production process does not lead to environment destructions" [3]. As such, it employs reduce, reuse and recycle techniques to minimize greenhouse gas emission and limit the use of natural resources such as limestone, clay, natural river sand, natural rocks that are being consumed but not returned back to the earth. This study built on a preliminary study conducted by the authors on the reuse of building demolition wastes and their potential usefulness in producing new concrete. More investigation scenarios were included in continuation of the previous work presenting and testing more options for sustainable concrete using recycled aggregates. Properties and characteristics of the prepared (RCA) were determined to check their consistency with those of NCA. The physical properties of fresh and hardened RCA included concrete were investigated with and without natural pozzolana being added to the mixtures. The effect of the RCA inclusion was verified via the check of the mechanical behavior of the produced concrete as the workability, compressive strength and durability were measured.

\section{Literature Review and Previous Studies}

Different trials for testing the suitability of using recycled aggregate (RA), derived from construction debris and demolition waste, for partial or entire replacement of virgin aggregate when making new concrete. [4], argued that RA “... could save about $60 \%$ of limestone resources and reduce $\mathrm{CO}_{2}$ emissions by about $15 \%-20 \%$ ". In recent years, intensive research output on the utilization of recycled aggregate concrete (RAC) has been reported yet there are some limitations recorded on its use pertaining to its long-term durability. The consulted publications outlined the outcomes for the evaluation of physical and mechanical properties of RAC. Absorption, aggregates texture size and gradation, specific gravity, density, mortar content, percentage and type of contamination, aggregate strength and abrasion resistance are the main properties considered and their effect in the concrete was investigated. It was found that variation in the RA properties, different environmental conditions in addition to the crushing process, contamination and impurities, affect the new concrete properties. Mortar adhered to RA leads to lower density, high absorption, and high abrasion loss. Moreover, sulphate and alkali contents cause expansive reactions which can be controlled if the maximum sulphate is in the range of $0.8-1.0 \%$ by mass and alkali content is below $3.5 \mathrm{~kg} / \mathrm{m}[5-8]$.

Numerous efforts were exerted to evaluate fresh and hardened properties of RAC. They indicated that the use of RA led to reduction in all mechanical properties, in addition to influencing the fresh stage properties and concrete durability due to high absorption and porosity [9, 10]. Consequently, more water is needed to achieve similar workability to that of NAC due to higher absorption capacity of RA which can be attributed to the presence of impurities and attached cement hydrates. [11] also confirmed the fact that as the RA content increases in the mix, the workability reduces especially at lower w/c ratio and in their study, it was found that the entrapped air content was similar when compared to normal concrete mix having a range of $2.4 \pm 0.2 \%$. There was no significant effect recorded regarding the air content up to $25 \%$ replacements. 50 to $100 \%$ replacement of virgin aggregates with RA decreases the compressive strength by 5 to $25 \%$ despite having some studies confirming the suitability of RA to replace up to $30 \%$ virgin aggregates without any effects on concrete strength. Strength gain for RCA concrete is lower than normal aggregate concrete (NAC) for the first 7 days but adversely, fine RA has a more detrimental effect on compressive strength than coarse RA $[12,13]$.

Thus, RA durability can be influenced by coarse aggregate replacement ratio, concrete age, $\mathrm{w} / \mathrm{c}$ ratio, and moisture content; generally, a lower w/c ratio generates a more durable concrete mix as stated by [14-17]. Argued that RAC is less durable due to the high porosity of RA. Consequently, optimizations to determine the percentage of RA that could be used without affecting the short and long-term performance were investigated and design equations based on data collected from many previous studies were proposed for that type of concrete $[18,19]$.

\section{Experimental Work and Material Characterization}

\subsection{Cement}

Ordinary Portland Cement (OPC) conforming to (BS-81121996) was used with physical properties outlined in table 1.

Table 1. Physical Properties of Portland cement.

\begin{tabular}{lll}
\hline Characteristics & Values Obtained & Standard Values (BS - 8112-1996) \\
\hline Normal Consistency & $32.5 \%$ & Not to be less than $26 \%$ and Not to be greater than $33 \%$. \\
Initial Setting Time & 2 hours $25 \mathrm{~min}$ & Not to be less than $60 \mathrm{minutes}$ \\
Final Setting Time & 3 hours $30 \mathrm{~min}$ & Not to be greater than $600 \mathrm{minutes}$ \\
Fineness & $2 \%$ & Not to be greater than $10 \%$. \\
Stability Size & $2 \mathrm{~mm}$ & Not to be greater than $10 \mathrm{~mm}$. \\
\hline
\end{tabular}




\subsection{Coarse Aggregates}

Quality and availability of RA are considered as the main factors towards stable use and introduction of RAC to the construction industry. The uncrushed gravel aggregate used in this study was obtained from a recycling plant which was established and directed towards reducing construction/demolition waste in Khartoum State, Sudan (refer to figure 1).
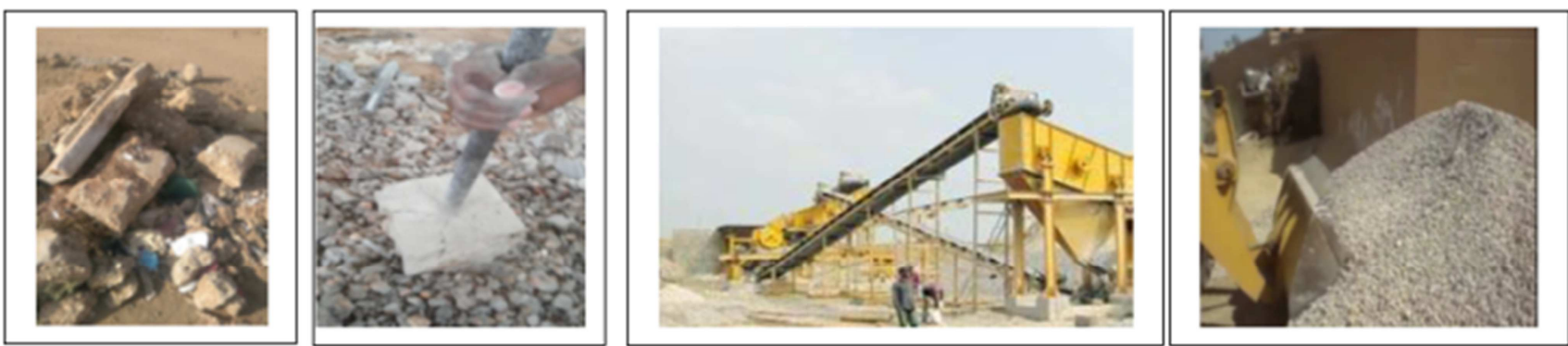

Figure 1. The aggregates recycling process.

The waste was received and processed to produce several products; however, the main product was aggregate. The recycling process involved crushing, separation of metals by a magnet, manual removal of other impurities (plastic, wood, etc...), and classification of aggregates to different grades based on particle size

NCA and RCA Gradation

The NCA and RCA used in the study had similar gradation as depicted in Tables 2 and 3.

Table 2. Gradation of natural coarse aggregates.

\begin{tabular}{lllll}
\hline Sieve Size (mm) & Retained Weight (kg) & Retained (\%) & Cumulative retained (\%) & Passing (\%) \\
\hline 20 & 0 & 0 & 0 & 100 \\
12.5 & 0.9 & 15 & 15 & 85 \\
10 & 2.1 & 35 & 50 & 50 \\
4.75 & 2.8 & 46.7 & 97.7 & $85-100$ \\
\hline
\end{tabular}

Table 3. Gradation of recycled coarse aggregates.

\begin{tabular}{llllll}
\hline Sieve Size (mm) & Retained Weight (kg) & Retained (\%) & Cumulative retained (\%) & Passing (\%) & Required (\%) \\
\hline 20 & 0 & 0 & 0 & 100 & 87.5 \\
12.5 & 0.75 & 12.5 & 12.5 & 54.2 & $45-100$ \\
10 & 2.0 & 33.3 & 45.8 & $40-85$ & 4.2 \\
4.75 & 3.0 & 50.0 & 95.8 & $0-10$ \\
\hline
\end{tabular}

Proprieties of RCA \& NCA

The results from Table 4 showed that specific gravity of NCA and RCA was accepted but the absorption of RCA was higher than that of NCA.

Table 4. Properties of (NCA) and (RCA).

\begin{tabular}{lll}
\hline Characteristics & NCA & RCA \\
\hline Specific gravity & 2.76 & 2.66 \\
Absorption & 0.44 & 0.98 \\
\hline
\end{tabular}

\subsection{Fine Aggregates}

Table 5. Sieve analysis of fine aggregates.

\begin{tabular}{lllll}
\hline Sieve Size (mm) & Weight retained $(\mathbf{k g})$ & Retained (\%) & Cumulative retained (\%) & Passing (\%) \\
\hline 4.75 & 81 & 8.1 & 8.1 & 91.9 \\
2.36 & 60 & 6 & 14.1 & 85.9 \\
1.4 & 121.5 & 12.15 & 26.25 & 73.74 \\
1.18 & 142 & 14.2 & 40.45 & 59.55 \\
0.600 & 192 & 19.2 & 59.65 & 40.35 \\
0.300 & 168 & 16.8 & 76.45 & 23.55 \\
0.150 & 187 & 18.7 & 95.15 & 4.85 \\
Pan & 48.5 & 4.85 & - & - \\
\hline
\end{tabular}




\section{Methodology}

\subsection{Development of Concrete Mixes}

The researchers designed and calculated the materials ratio for 8 different Concrete Mix scenarios, according to the British Building Research Center. The targeted compressive strength value was $\left(25 \mathrm{~N} / \mathrm{mm}^{2}\right)$ and the slump value was within the range of $(60-180) \mathrm{mm}$ and the adopted concrete mix scenarios were as follows:

1. Reference mix including (NCA).
2. A mix including (RCA) replacing $25 \%$ (NCA).

3. A mix including (RCA) replacing 50\% (NCA).

4. A mix including (RCA) replacing 75\% (NCA).

5. A mix including (RCA) replacing $100 \%$ (NCA)

6. A mix including (RCA) replacing $100 \%$ (NCA) and Pozzolana replacing $10 \%$ of the cement weight.

7. A mix including (RCA) replacing $100 \%$ (NCA) and Pozzolana replacing $20 \%$ of the cement weight.

8. A mix including (RCA) replacing 100\% (NCA) and Pozzolana replacing $30 \%$ of the cement weight.

Table 6. Materials ratios in concrete mixes per cubic meter.

\begin{tabular}{|c|c|c|c|c|c|c|}
\hline Concrete Mix Scenario & Cement (Kg) & Water (Kg) & Sand $(\mathrm{Kg})$ & $\mathrm{NCA}(\mathrm{Kg})$ & RCA (Kg) & Pozzolana (Kg) \\
\hline 1 & 325 & 195 & 641 & 1189 & - & - \\
\hline 2 & 325 & 195 & 641 & 891.75 & 297.25 & - \\
\hline 3 & 325 & 195 & 641 & 594.5 & 594.5 & - \\
\hline 5 & 325 & 195 & 641 & - & 1189 & - \\
\hline 6 & 292.5 & 195 & 641 & - & 1189 & 32.5 \\
\hline 7 & 260 & 195 & 641 & - & 1189 & 65 \\
\hline
\end{tabular}

\subsection{Mixing and Casting of Cubes}

All required materials for concrete mixes were prepared at laboratory, using $(150 \times 150 \times 150) \mathrm{mm}$ casting cubes.

\section{Results and Discussion}

\subsection{Slump Test}

The slump test results shown in figure 2 depict the conformance of all results to the specifications (slump range: $60-180 \mathrm{~mm}$ ). When RCA was introduced the workability decreased in the range of $4.2-14.3 \%$ with increasing replacement ratios of RCA up to a maximum of $20.2 \%$ with $100 \%$ RCA in comparison to NCA. On the other side, an increase in the range of $3.2-7.4 \%$ was noticed with the inclusion of Pozzolana with 100\% RCA concrete. In its fresh state, the optimum ratio was achieved with the full replacement of NCA with RCA and the inclusion of $20 \%$ Pozzolana.

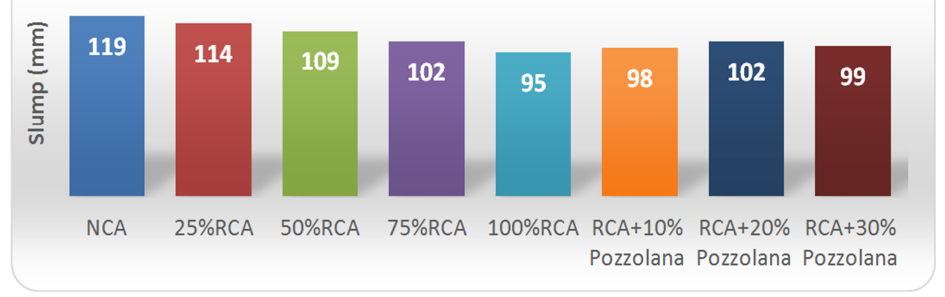

Figure 2. Slump test results for the different mix scenarios.

\subsection{Compressive Strength Test}

Compressive strength results are presented in figures 3, 4 $\& 5$. The results were consistent for 7 days and 28 days with the strength decreasing as the RCA replacement percentage increases. However, with $100 \%$ RCA and inclusion of pozzolana, an increase in compressive strength was noticed yielding the targeted design strength at $10 \%$ pozzolana inclusion.

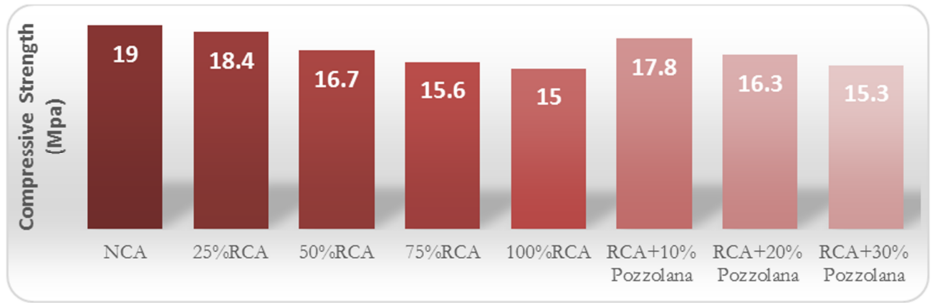

Figure 3. 7 days Compressive Strength Test Results. 


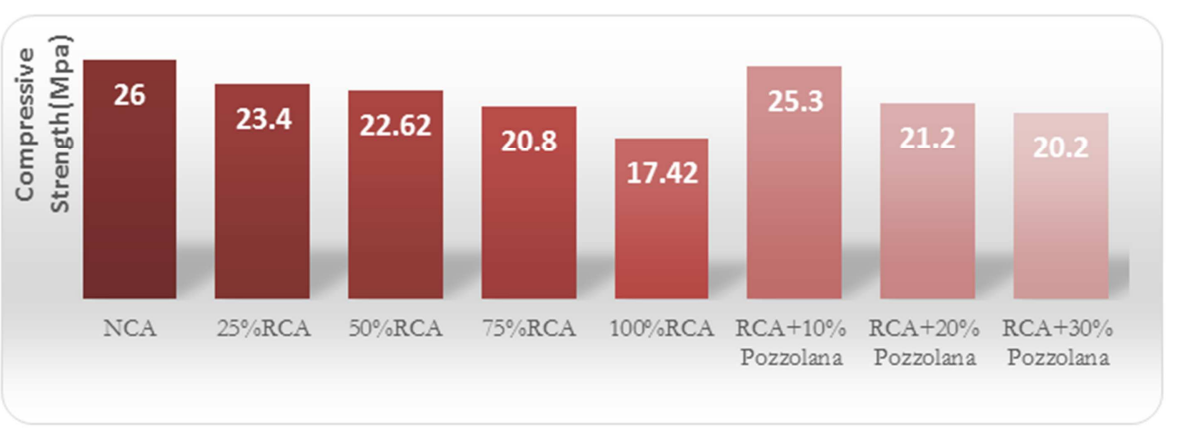

Figure 4. 28 days Compressive Strength Test Results.

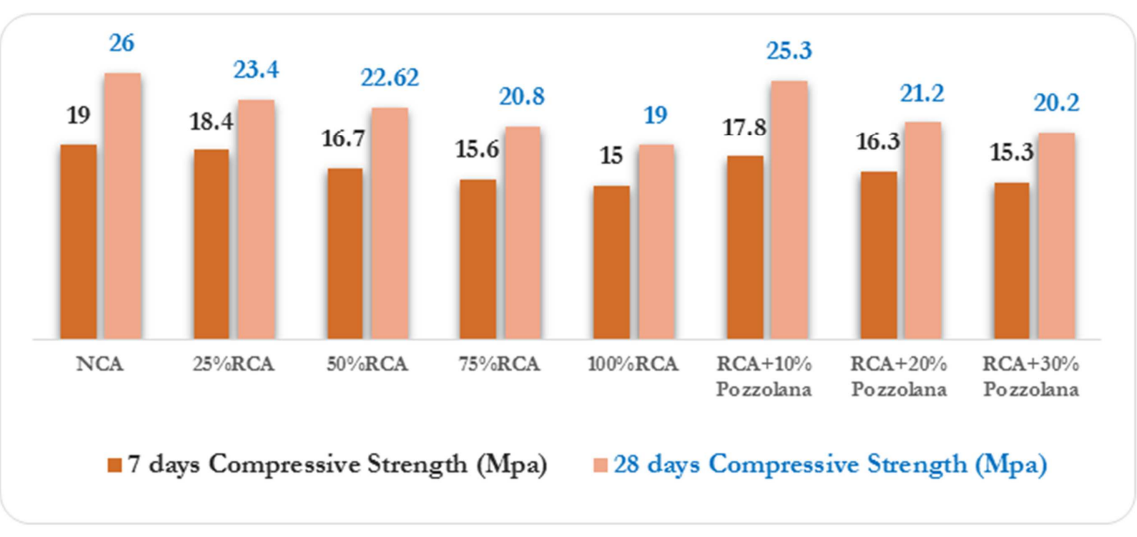

Figure 5. 7 and 28 days Compressive Strength Test Results.

\subsection{Durability Test}

The results for the durability test revealed a drop in the wave speed value when the natural aggregates were used was $100 \%$ replaced by the recycled aggregates while an increased was witnessed when obvious different percentage of Pozzolana was added to mix. The optimum result was achieved when the coarse aggregates were completely replaced and $10 \%$ Pozzolana was added (refer to figure 6).

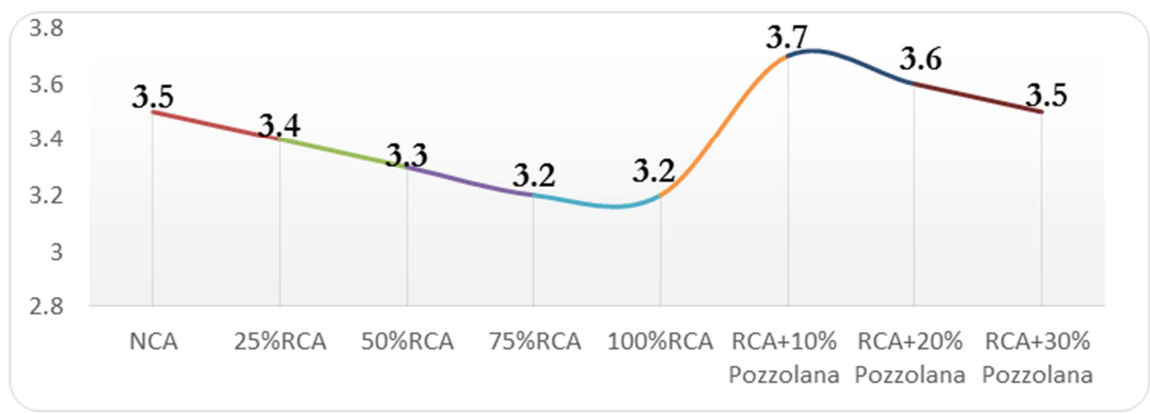

Figure 6. Durability Test Results.

\section{Conclusion}

The obtained results were considered promising giving reasonable indicators for the potential usefulness of recycled aggregates and the local Pozzolana when used in concrete mixes. More tests might be needed for further confirmation with various percentages of Pozzolana and different mix combinations. It is thus recommended to repeat the mix design considering different percentages of the recycled aggregates or the Pozzolana in the mix.

\section{References}

[1] Mehta, P. K.. "Sustainable Cements and Concrete for the Climate Change Era - A Review". Proc. 2nd International Conference on Sustainable Construction Materials and Technologies. Ancona, Italy, June 28-30. (2010).

[2] McDonough, W. et al. 1992 in Naik \& Moriconi. Environmental-friendly durable concrete made with recycled materials for sustainable concrete construction. Hannover, Germany, (2010). 
[3] Salma Mahmoud and Eltahir. Elshiekh, "The Potential Usefulness of Recycled Aggregates and Pozzolana in Producing Green Concrete in Sudan," International Journal of Structural and Civil Engineering Research, Vol. 7, No. 2, pp. 113-117, May 2018. doi: 10.18178/ijscer.7.2.113-117.

[4] Xiao, J., Fana, L. Y., \& Huang, X. An overview of study on recycled aggregate concrete in China (1996-2011). Construction and Building Materials, 31, 364-383. (2012b).

[5] McNeil, K., \& Kang, T. H.-K. Recycled concrete aggregates: A review. International Journal of Concrete Structures and Materials, 7 (1), 61-69. (2013).

[6] De Brito, J., \& Saikia, N. Recycled aggregate in concrete: Use of industrial, construction and demolition waste. 445 p., London, UK: Springer. (2013).

[7] Akbarnezhad, A., Ong, K. C. G., Tam, C. T., \& Zhang, M. H.. Effects of the parent concrete properties and crushing procedure on the properties of coarse recycled concrete aggregates. Journal of Materials in Civil Engineering, 25 (12), 1795-1802. (2013).

[8] Silva, R. V., de Brito, J., \& Dhir, R. K. Prediction of the shrinkage behavior of recycled aggregate concrete: A review. Construction and Building Materials, 77, 327-339. (2015).

[9] Ulloa, V. A., García-Taengua, E., Pelufo, M. J., Domingo, A., $\&$ Serna, P. New views on effect of recycled aggregates on concrete compressive strength. ACI Materials Journal, 110 (6), 1-10. (2013).

[10] Xiao, J., Li, L., Tam, V. W., \& Li, H. The state of the art regarding the long-term properties of recycled aggregate concrete. Structural Concrete, 15 (1), 3-12. (2014).

[11] Medina, C., Zhu, W., Howind, T., Sanchez de Rojas, M. I., \&
Frias, M. Influence of mixed recycled aggregate on the physical-mechanical properties of recycled concrete. Journal of Cleaner Production, 68 (1), 216-225. (2014).

[12] Garg, P., Singh, H., \& Walia, B. S. Optimum Size of Recycled Aggregate. GE-International Journal of Engineering Research. pp. 35-41, (2013).

[13] Sim, J., \& Park, C. Compressive strength and resistance to chloride ion penetration and carbonation of recycled aggregate concrete with varying amount of fly ash and fine recycled aggregate. Waste Management, 31 (11), 2352-2360. (2011).

[14] Thomas, C., Setien, J., Polanco, J. A., Alaejos, P., \& Sanchez de Juan, M. Durability of recycled concrete aggregate. Construction and Building Materials, 40, 1054-1065. (2013).

[15] Fathifazl, G., \& Razaqpur, A. G. Creep rheological models for recycled aggregate concrete. ACI Materials Journal, 110 (2), 115-126. (2013).

[16] Kou, S. C., \& Poon, C. S.. Enhancing the durability properties of concrete prepared with coarse recycled aggregate. Construction and Building Materials, 35, 69-76. (2012).

[17] Chen, H.-G., \& Ying, J.-W. Analysis of factors influencing durability of recycled aggregate: A review. Paper presented at the electric technology and civil engineering, Lushan. (2011).

[18] Kwan, W. H., Ramli, M., Kam, K. J., \& Sulieman, M. Z. Influence of the amount of recycle coarse aggregate in concrete design and durability properties. Construction and Building Materials, 26 (1), 565-573. (2012).

[19] Manzi, S., Mazzotti, C., \& Bignozzi, M. C. Short and longterm behavior of structural concrete with recycled concrete aggregate. Cement \& Concrete Composites, 37, 312-318. (2013). 